\title{
Use and users of electronic journals at Catalan universities: the results of
}

\section{a survey}

NOTICE: This is the author's version of a work accepted for publication by Elsevier. Changes resulting from the publishing process, including peer review, editing, corrections, structural formatting and other quality control mechanisms, may not be reflected in this document. Changes may have been made to this work since it was submitted for publication. A definitive version was subsequently published in The Journal of Academic Librarianship [VOL. 33, ISSUE 1], January 2007, doi:10.1016/j.acalib.2006.08.012.

Àngel Borrego

Lecturer

University of Barcelona; Faculty of Library and Information Science

borrego@ub.edu

Lluís Anglada

Director

Consortium of Academic Libraries of Catalonia (CBUC)

langlada@cbuc.es

Maite Barrios

Lecturer

University of Barcelona; Faculty of Library and Information Science

mbarrios@ub.edu

Núria Comellas

Project Manager

Consortium of Academic Libraries of Catalonia (CBUC)

ncomellas@cbuc.es 


\section{Abstract:}

We present the results of a survey on the use of electronic journals by the academic staff of the universities belonging to the Consortium of Academic Libraries of Catalonia (CBUC). The results show that a high proportion of teaching and research staff are aware of the collection of electronic journals and that there is an increasing preference for the electronic to the detriment of the printed format. The collection of electronic journals is highly valued and most users expect to increase their use of them during the next few years. The results also confirm the importance of discipline and age as explanatory factors of the use of electronic journals.

\section{Introduction and objectives}

This article presents the results of a study on the use of electronic journals by the academic staff of the Consortium of Academic Libraries of Catalonia (CBUC). The CBUC is composed of the eight public Catalan universities ${ }^{1}$ and the National Library, though it allows other institutions to participate as users. In January 2006, the CBUC had subscribed consortially to 7,200 electronic journals which can be accessed by the users of the universities belonging to the Consortium.

The main aim of the study was to supplement the results obtained in earlier studies, ${ }^{2}$ which had provided very interesting general information on the use of the journal packages licensed by the CBUC. However because these earlier studies had been based exclusively on the analysis of the web access data supplied by the publishers, they failed to give information on the characteristics of the users.

The present study aims to extend the information available on the use of the electronic journal collection in order to broaden the available knowledge on a series of questions:

- The level of awareness of the collection of electronic journals.

- Whether users prefer the electronic or printed format and the advantages and disadvantages that they observe in each format.

- The demographic characteristics of the users of electronic journals-discipline, age and academic position—and the effect of these variables on use. 
- The characteristics of use: the reasons for consulting the journals and the place of access.

- The level of satisfaction with the coverage of the electronic journal collection.

\section{Literature review}

There have been many studies of users of electronic journals in the professional literature in the last few years. In a recent exhaustive review of the literature on the subject, Tenopir ${ }^{3}$ analyzed the results of over 200 studies of the use of electronic resources in libraries published between 1995 and 2003. The main conclusion of this review is that electronic resources have been rapidly adopted in academic spheres, though the behavior varies according to the discipline.

Jamali, Nicholas and Huntington ${ }^{4}$ also reviewed the conclusions of several papers that used log analysis to study the use and users of electronic journals. These papers gave contradictory conclusions on the volume of use of subscriptions through Big Deals ${ }^{5}$, but showed a high degree of concentration in the use of the titles and a clear preference for PDF rather than HTML format. They also provided interesting information on the behavior patterns of users and the growing preference for searching to the detriment of browsing as the main means of accessing information.

The surveys of users of electronic resources carried out so far have been summarized by BarIlan and Fink. ${ }^{6}$ They show that:

- Use of electronic journals increases with time.

- Age and/or academic position are inversely related to the use of electronic media and journals.

- There is a gradual reduction in the use of printed journals as users prefer and use the electronic format more.

- With increased use, users access the electronic format more frequently.

- The use of a journal is not necessarily an indication of the preference of users. There may be an increase in the acceptance and frequency of use of the electronic format merely because the traditional print format is no longer easily available. 
- When respondents were asked about the advantages of electronic journals, accessibility and desktop access, home access, ease of retrieval and hyperlinks to outside content were the arguments cited most often. On the other hand, the disadvantages of electronic journals mentioned most often were the lack of back issues and problems with reading a text from the computer screen.

One of the aspects most analyzed in the studies of users carried out so far is that of the variables determining their behavior in the use of electronic resources. Clearly different behaviors can be identified according to variables such as discipline, age and academic position.

With regard to the discipline, it seems that teaching and research staff in exact and natural (hard) sciences, who were in fact the first to adopt electronic journals, are the most active users of titles in electronic format. ${ }^{7,8}$ This may be related to the fact that, according to several studies, ${ }^{9}$ involvement in research is the best predictor of the use of electronic resources. According to Tenopir and King, ${ }^{10}$ seventy-five percent of journal readings are for research and forty-one percent for teaching. In a recent study among the users of OhioLINK, ${ }^{11}$ the consultation of electronic journals by academic staff was also research-related (work on PhD and master's theses, preparation of project applications, etc.), whereas the preparation of teaching material was mentioned less often. In the study by Bar-Ilan, Peritz and Wolman, ${ }^{12}$ most of the respondents $(69.2 \%)$ stated that they used databases and electronic journals for both teaching and research, compared with $23.9 \%$ who used them exclusively for research and only $0.6 \%$ who used them exclusively for teaching.

Differences in behavior according to age (a question that must continue to be studied as new generations of teaching and research staff with good computer skills emerge), status and academic position have also been observed. ${ }^{13}$ According to Bar-llan, Peritz and Wolman, ${ }^{14}$ the most active users of electronic journals are the younger members of the teaching and research staff. On the other hand, a recent survey of the medical teaching and research staff at the University of Tennessee ${ }^{15}$ showed that age was not an influential factor in whether the 
respondents read articles on paper or in electronic format. However, these results did not coincide with those obtained by the same researchers ${ }^{16}$ among astronomical scientists.

The relationship between the use of electronic journals and academic position has also been analyzed, though it may often be contaminated by the relation between age and academic position: as time goes by, researchers progress in their careers and obtain higher positions in the academic hierarchy. Gender does not seem to affect use and has therefore not been considered in this study.

Bar-Ilan, Peritz and Wolman ${ }^{17}$ found that $48.9 \%$ of the respondents preferred the electronic version of the titles, $28.2 \%$ preferred the printed version and $22.9 \%$ expressed no preference. However, whereas in life sciences $64.6 \%$ preferred the electronic version, in humanities $56.5 \%$ preferred the printed version. Siebenberg, Galbraith and Brady ${ }^{18}$ carried out a study of changes in the use of printed and electronic journals in three disciplines: chemistry, mechanical engineering and physics. For this purpose they compared the use of the printed and electronic versions of 277 titles in 1998, when only the printed versions were available, and 2001, when the printed and electronic versions of the same titles were available. The results showed that between 1998 and 2001 the use of titles that were only available in the printed version increased, and there was also a general increase in the use of the printed versions of the journals that were also available in electronic format. In these three disciplines the printed versions accounted for $25 \%$ of the total consumption of the titles that were available in both versions.

\section{Methodology}

The methods used in earlier studies of users of electronic library resources vary greatly. Tenopir $^{19}$ identifies studies carried out using transactional analysis techniques, discussion groups, observation in experimental and natural environments and interviews and surveys enquiring about preferences, behaviors and critical incidents. 
In the present study it was decided to carry out a survey of all the academic staff of the universities belonging to the CBUC. The questionnaire was divided into three parts. Firstly, it included a series of questions on the demographic data of the respondents: the university at which they worked and their discipline, age and academic position. It also included a question on whether the respondents were aware of the electronic journal collection offered by their university in order to determine whether the replies to the rest of the questions were based on real knowledge of the service.

The second part of the questionnaire contained four questions on the respondents' use of the journal collection. Firstly, it attempted to determine whether the users preferred to consult electronic or printed journals and, if the latter was the case, to identify the reasons for this behavior-lack of familiarity with the digital medium, lack of Internet connection, non-availability of electronic journals in their discipline, etc. The respondents were then asked whether they would stop using the printed version of a title if the electronic version were available, the place where they accessed electronic journals and the reason for their use.

Finally, the third part of the questionnaire included a question in which they were asked to evaluate the coverage of the collection of printed and electronic journals in their institution and two questions on how they expected their use of printed and electronic titles to develop in the next few years.

The questionnaire was distributed to all academic staff of the universities belonging to the CBUC. According to the figures of the IDESCAT (Statistics Institute of Catalonia) ${ }^{20}$, the population analyzed consisted of a total of 14,855 persons. Between May and June 2005, each university distributed the questionnaire to its academic staff. It was sent mainly by post, though in a few cases it was sent by e-mail and printed by the respondents. The 2,682 replies received represented a response rate of $18.05 \%$, which is adequate considering that the replies were totally voluntary and non-incentivated. 


\section{Data analysis}

The items of the survey were analyzed descriptively by percentages for the qualitative variables, and indicators such as the median and the interquartile deviation were used for the ordinal variables. The qualitative variables were related by means of the chi square test, and the contingency coefficient for each statistically significant comparison was calculated in order to study the strength of the association. Pairwise comparisons were made using the adjusted residuals of the test. The relationship between the quantitative ordinal variables was analyzed by dependent samples using the Wilcoxon Signed-Rank Test. The contrasts were considered statistically significant if $\alpha<0.01$.

\section{Results}

\section{Characteristics of the subjects}

The general distribution of the respondents by disciplines was relatively homogeneous: $21.0 \%$ were in Biomedicine, 19.4\% in Exact and Natural Sciences, $19.2 \%$ in Engineering, $27.0 \%$ in Social Sciences and $13.3 \%$ in Humanities.

The majority of the respondents were in the $31-40$ and $41-50$ age groups, which represented 34.8 and $32.4 \%$ of the responses respectively. However, a statistically significant relationship was observed between the discipline of the respondents and their age $\left(\chi^{2}=85.1, \mathrm{df}=16\right.$, $\alpha<0.001$, Contingency Coefficient $(C C)=0.18)$. Biomedicine showed a high proportion of respondents in the 41-50 and 51-60 age groups, whereas Exact and Natural Sciences showed a high proportion in the under-30 group, and Social Sciences and Engineering showed a high proportion in the 31-40 age group.

The percentages of response according to academic position and the percentages gathered from the IDESCAT figures for the survey population were similar for all the categories except associate professors (professionals who work at the university part-time), who represent $41.1 \%$ of the academic staff but only $22.3 \%$ of the sample. 


\section{Awareness and use of the electronic journal collection}

Knowledge of the electronic journal collection was high, with $95.3 \%$ of the respondents stating that they were aware of the journal collection in this medium. The figure was very similar for the different disciplines, and was higher than $90 \%$ in all cases.

With regard to the preferred media, $52 \%$ of the respondents stated that they used electronic journals exclusively or mainly. Furthermore, $28 \%$ used both media to a similar extent. As shown in Table 1 and Figures 1 and 2, the use of the electronic journal collection shows a statistically significant relationship with the discipline, the age of the respondents and their academic position, though the strength of these relationships was in most cases low. The analysis of the adjusted residuals of the chi square test showed that respondents in the disciplines of Biomedicine and Engineering use exclusively or mainly electronic journals and respondents in Exact and Natural Sciences use mainly electronic journals, whereas respondents in Social Sciences and Humanities use mainly printed journals. By age groups, respondents under the age of 40 use mainly electronic journals, whereas respondents over the age of 51 use exclusively or mainly printed journals. By academic positions, though there was a statistically significant relationship, no clear differential profile was observed in the study of the adjusted residuals.

[Place about here: Table 1. Relationship between use of the electronic journal collection and discipline, age and academic position]

[Place about here: Figure 1. Relationship between use of the journal collection and discipline]

[Place about here: Figure 2. Relationship between use of the journal collection and age]

Respondents who stated that they use exclusively or mainly printed journals (536 persons, $19.98 \%)$ were asked to give the reasons for this preference. The reason mentioned by over half the respondents who had chosen one of these two options was the lack of familiarity with electronic journals $(57.8 \%)$. On the other hand, $13.8 \%$ stated that there were no electronic 
journals in their discipline and only $2 \%$ stated that they did not have an Internet connection (Figure 3). The reasons for not using electronic journals seem to be related to the academic position $\left(\chi^{2}=19.23, d f=6, \alpha=0.004, C C=0.2\right)$. Among academic staff who did not use electronic journals, $67.3 \%$ of associate professors stated that they were not familiar with them, compared with only $41.8 \%$ of senior professors. Among tenured professors the adjusted residuals did not show statistically significant differences.

[Place about here: Figure 3. Reasons for using exclusively or mainly printed journals]

Of the respondents answering this question, $26 \%$ chose the option "Other reasons", but in many cases this meant that there were few titles in their disciple. Perhaps the previous option "There are no electronic journals in my discipline" was badly worded. There also seems to be an association between the quality of the titles and the medium in which they are published, the best titles being associated with the printed format, which is preferred for consultation. Some respondents preferred the printed format because they needed to consult back issues that were only available on paper. Some preferred it because of habit and some preferred reading on paper. Finally, some respondents preferred paper because of technological shortcomings. Many of the replies coincided with those obtained in studies asking the users to identify the main disadvantages of using electronic journals.

When the respondents were asked whether they would be prepared to stop using the printed version of a title if the electronic version were available, $76 \%$ stated that they would. The acceptance of change is related to the discipline $\left(\chi^{2}=44.52, \mathrm{df}=4, \alpha<0.001, \mathrm{CC}=0.13\right)$, age $\left(\chi^{2}\right.$ $=99.96, \mathrm{df}=4, \alpha<0.001, \mathrm{CC}=0.2)$ and academic position of the respondent $\left(\chi^{2}=33.77, \mathrm{df}=9\right.$, $a<0.001, C C=0.1)$. The analysis of the adjusted residuals shows that the number of persons who would be prepared to stop using the printed version of a title if it were available in electronic format was higher in Biomedicine and Exact and Natural Sciences than in Social Sciences and Humanities (Figure 4). Again, respondents under the age of 40 were less reluctant to change than respondents over 51 (Figure 5). A favorable attitude towards change was more common 
among respondents who were familiar with the electronic journal collection $\left(\chi^{2}=43.41, d f=1\right.$, $\alpha<0.001, C C=0.13)$.

[Place about here: Figure 4. Relationship between discipline and willingness to change to the electronic version]

[Place about here: Figure 5. Relationship between age and willingness to change to the electronic version]

The great majority of the respondents stated that they consulted electronic journals exclusively from their offices $(60.3 \%)$ or from both their offices and their homes $(28.4 \%)$. Far fewer consulted them only from home or from the library.

Electronic journals were consulted for both research and teaching by $53.6 \%$ of the respondents. They were consulted only for research by $37.4 \%$ and only for teaching by $2.7 \%$. Taking into account these three main reasons for consultation (expressed by $93.7 \%$ of the respondents), it is observed that the reason for using electronic journals was related to the discipline of the respondents $\left(\chi^{2}=136.79, \mathrm{df}=8, \alpha<0.001, \mathrm{CC}=0.24\right)$, their age $\left(\chi^{2}=110.96 \mathrm{df}=6, \alpha<0.001, \mathrm{CC}=\right.$ $0.21)$ and their academic position $\left(\chi^{2}=31.19 \mathrm{df}=6, \alpha<0.001, \mathrm{CC}=0.12\right)$. The analysis of the adjusted residuals shows that respondents in Exact and Natural Sciences and Engineering mainly use journals for research, whereas those in Biomedicine use them for both teaching and research (Figure 6). Disaggregated by age, respondents under the age of 30 mainly use them for research, respondents in the 41-50 age group use them for both teaching and research, and respondents over the age of 51 use them for teaching and research or only for teaching (Figure 7). Disaggregated by academic position, only the associate professors showed a high proportion of use for teaching (35.9\%).

[Place about here: Figure 6. Relationship between discipline and reason for use]

[Place about here: Figure 7. Relationship between age and reason for use] 


\section{Evaluation of the collection of journals}

The questionnaire asked the respondents to evaluate the level of coverage of the collections of electronic and printed journals available in their institution on a scale of 1 to 7 . In general, the evaluation of the coverage was high for both printed and electronic journals. In both cases, the median was 5 points, with an interquartile width of 3 points for printed journals and 2 points for electronic journals. If we take into account the discipline of the respondent, as shown in Table 2 , the respondents in Biomedicine, Exact and Natural Sciences and Engineering gave a significantly higher value to the collection of journals in electronic format, whereas the respondents in Social Sciences and Humanities gave a significantly higher value to printed journals.

[Place about here: Table 2. Evaluation of the collection of printed and electronic journals by discipline]

By age groups, as shown in Table 3, statistically significant differences were only observed among respondents of the $31-40$ and $41-50$ age groups, who gave a higher score to the electronic journal collection. No statistically significant differences were observed in the other age groups.

[Place about here: Table 3. Evaluation of the collection of printed and electronic journals by age groups]

When the users were asked about how their use of printed journals would evolve in the next few years, $15.4 \%$ stated that it would increase, $27.8 \%$ that it would not vary, $43 \%$ that it would decrease and $13.8 \%$ that they would stop using them.

The perception of the future use of printed journals showed a statistically significant relationship with the discipline of the respondent $\left(\chi^{2}=160.47, \mathrm{df}=16, \mathrm{a}<0.001, \mathrm{CC}=0.25\right)$. The adjusted residuals showed a higher proportion of Humanities respondents who thought that their use of 
printed journals would increase or remain the same, whereas a higher proportion of those in Biomedicine, Exact and Natural Sciences and Engineering considered that they would use them less or stop using them (Figure 8). Age is also related to this perception $\left(\chi^{2}=50.94, \mathrm{df}=16\right.$, $\alpha<0.001, C C=0.14) . A$ larger proportion of older respondents believed that their use of printed journals would not change or would increase to some extent, whereas a higher proportion of younger respondents believed that they would use them less or stop using them (Figure 9).

[Place about here: Figure 8. Relationship between discipline and expected future use of printed journals]

[Place about here: Figure 9. Relationship between age and expected future use of printed journals]

With regard to their future use of electronic journals, $91.1 \%$ of the respondents thought that they would use them more in the next few years. Only $8.6 \%$ believed that there would be no change in their use and fewer than $1 \%$ believed that they would use them less or stop using them. The proportion of respondents who thought they would use electronic journals more was around $90 \%$ in all the disciplines.

\section{Conclusions}

The results of the study offer significant information on the level of awareness and use of electronic journals in Catalan universities, the characteristics of the users and their evaluation of the journal collection. Firstly, though they have been incorporated in library collections only recently, there is a high level of awareness of the collection of electronic titles among teaching and research staff, with $95 \%$ of the respondents stating that they are aware of the electronic journal collection offered by their institution. Respondents who use electronic journals less show a lack of awareness of the collections rather than a resistance to change. Therefore, these figures can be clearly used to identify the groups in which more and better action can be taken with regard to training of users and marketing of electronic resources. 
Not only are the users aware of the availability of electronic titles, but many use them as the main medium of access to scientific and technical information: over half the respondents stated that they used electronic journals exclusively or mainly. However, the preference for the electronic format is related to the discipline and age of the respondents and is higher among academic staff in Biomedicine, Engineering and Exact and Natural Sciences, and among the younger respondents.

Users accept that the number of electronic titles is increasing and the number of paper subscriptions is decreasing, and they even prefer the electronic format: $76 \%$ of the respondents stated that they would stop using the printed version of a title if they had access to the electronic version. Again, the respondents in Biomedicine and Exact and Natural Sciences and the younger respondents were more favorable to change, whereas those in Social Sciences and Humanities and the older users were more reluctant.

The study showed that research is the main reason for using electronic journals. However, a strong correlation was also observed between the reason for consulting the journals and the age of the respondents. Younger users who are in the process of consolidating their careers use electronic journals particularly for research, whereas older respondents use them for both research and teaching and a significant percentage only for teaching. According to these figures, the greater use of electronic journals among young academic staff could be due not only to their greater familiarity with new technologies, but also to the fact that they are more active in carrying out research with a view to consolidating their scientific careers.

The high level of awareness and use of electronic journals, and the preference for this medium in many cases, led users to prefer electronic journals to printed journals in Biomedicine, Exact and Natural Sciences and Engineering. The respondents of Social Sciences and Humanities, on the other hand, preferred printed journals. Finally, regardless of the discipline or age of the respondents, the vast majority considered that their use of electronic journals will increase in the next few years. 


\section{Notes and References}

1. The eight universities belonging to the CBUC are the University of Barcelona, the Autonomous University of Barcelona, the Technical University of Catalonia, the Pompeu Fabra University, the University of Girona, the University of Lleida, the Rovira i Virgili University and the Open University of Catalonia. The study also included figures for two associate universities of the Consortium: the Jaume I University and the University of Vic.

2. Cristóbal Urbano, Lluís Anglada, Àngel Borrego, Carme Cantos, Antoni Cosculluela \& Núria Comellas, "The Use of Consortially Purchased Electronic Journals by the CBUC (20002003)," D-Lib Magazine 10 (June 2004). Available:

http://www.dlib.org/dlib/june04/anglada/06anglada.html (accessed February 27, 2006).

3. Carol Tenopir, Use and users of electronic library resources: an overview and analysis of recent research studies (Washington, DC: Council on Library and Information Resources, 2003). Available: http://www.clir.org/pubs/reports/pub120/pub120.pdf (accessed February $27,2006)$.

4. Hamid R. Jamali, David Nicholas \& Paul Huntington, "The use and users of scholarly ejournals: a review of log analysis studies," Aslib Proceedings 57 (2005): 554-571.

5. Basically, a Big Deal is a package purchase in which a consortium of libraries purchases all of a publisher's journal titles in digital form for all members of the consortium.

6. Judit Bar-llan \& Noa Fink, "Preference for electronic format of scientific journals - a case study of the Science Library users at the Hebrew University," Library \& Information Science Research 27 (2005): 363-376.

7. Erin T. Smith, "Changes in Faculty Reading Behaviors: The Impact of Electronic Journals on the University of Georgia," Journal of Academic Librarianship 29 (May 2003): 162-167.

8. Judit Bar-llan, Bluma C. Peritz \& Yecheskel Wolman, "A survey of the use of electronic databases and electronic journals accessed through the web by the academic staff of Israeli universities," Journal of Academic Librarianship 29 (November 2003): 346-361.

9. Tenopir, "Use and Users," p. 29. 
10. Carol Tenopir \& Donald W. King, Towards Electronic Journals: Realities for Scientists, Librarians, and Publishers (Washington, DC: Special Libraries Association, 2000), p. 169.

11. Tschera Harkness Connell, Sally A. Rogers \& Carol Pitts Diedrichs, "OhioLINK electronic journal use at Ohio State University," Portal: Libraries and the Academy 5 (2005): 371-390.

12. Bar-llan, Peritz \& Wolman, "A survey," p. 354.

13. Tenopir, "Use and Users," p. 30-31

14. Bar-llan, Peritz \& Wolman, "A survey," p. 351.

15. Amy Bush, Donald W. King \& Carol Tenopir, "Medical faculty's use of print and electronic journals: changes over time and in comparison with scientists," Journal of the Medical Library Association 92 (2004): 233-241.

16. Carol Tenopir, Donald W. King, Peter Boyce, Matt Grayson \& Keri-Lynn Paulson, "Relying on electronic journals: Reading patterns of astronomers," Journal of the American Society for Information Science and Technology 56 (2005): 786-802.

17. Bar-llan, Peritz \& Wolman, "A survey," p. 355.

18. Tammy R. Siebenberg, Betty Galbraith, \& Eileen E. Brady, "Print versus electronic journal use in three sci/tech disciplines: what's going on here?," College and Research Libraries 65 (2004): 427-438.

19. Tenopir "Use and Users," p. 10-11.

20. Idescat, Anuari estadístic de Catalunya (Barcelona: Idescat, 2005), p. 537. Available: http://www.idescat.net/cat/idescat/publicacions/anuari/aec.html (accessed February 27, 2006). 
Table 1. Relationship between use of the electronic journal collection and discipline, age and academic position

\begin{tabular}{lcccc}
\hline & $\chi^{2}$ & $\mathbf{d f}$ & $\mathbf{p}$ & $\mathbf{C C}$ \\
\hline Discipline & 376.55 & 16 & $<0.001$ & 0.4 \\
Age & 122.59 & 16 & $<0.001$ & 0.2 \\
Professional category & 98 & 16 & $<0.001$ & 0.2 \\
\hline$\chi^{2}:$ Chi square test, df: degrees & of & freedom, p: level of \\
significance, CC: Contingency Coefficient & & &
\end{tabular}


Table 2. Evaluation of the collection of printed and electronic journals by discipline

\begin{tabular}{|c|c|c|c|c|c|}
\hline & & $\mathbf{n}$ & Md (IQR) & $\mathbf{Z}$ & $\alpha$ \\
\hline Biomedicine & $\begin{array}{l}\text { Printed } \\
\text { Electronic }\end{array}$ & 442 & $\begin{array}{l}4(2) \\
5(2)\end{array}$ & 5.83 & $<0.001$ \\
\hline Social Sciences & $\begin{array}{l}\text { Printed } \\
\text { Electronic }\end{array}$ & 566 & $\begin{array}{l}5(2) \\
4(2)\end{array}$ & 5.81 & $<0.001$ \\
\hline Exact and Natural Sciences & $\begin{array}{l}\text { Printed } \\
\text { Electronic }\end{array}$ & 429 & $\begin{array}{l}4(3) \\
5(2)\end{array}$ & 8.45 & $<0.001$ \\
\hline Engineering & $\begin{array}{l}\text { Printed } \\
\text { Electronic }\end{array}$ & 388 & $\begin{array}{l}4(2) \\
5(2)\end{array}$ & 8.49 & $<0.001$ \\
\hline Humanities & $\begin{array}{l}\text { Printed } \\
\text { Electronic }\end{array}$ & 260 & $\begin{array}{c}5(2.75) \\
4(2)\end{array}$ & 5.2 & $<0.001$ \\
\hline
\end{tabular}


Table 3. Evaluation of the collection of printed and electronic journals by age groups

\begin{tabular}{llcccc}
\hline & & $\mathbf{n}$ & Md (IQR) & $\mathbf{Z}$ & $\alpha$ \\
\hline \multirow{2}{*}{ Under 30 } & Printed & 241 & $5(1.5)$ & \multirow{2}{*}{0.45} & $\mathrm{~ns}$ \\
& Electronic & & $5(1)$ & & \\
Printed & 770 & $4(2)$ & & \\
& Electronic & & $4(2)$ & 6.05 & $<0.001$ \\
$41-50$ & Printed & 716 & $4(3)$ & & \\
& Electronic & & $5(3)$ & 3.36 & 0.001 \\
$51-60$ & Printed & 340 & $5(2)$ & & \\
& Electronic & & $5(2)$ & 0.85 & $\mathrm{~ns}$ \\
Over 60 & Printed & 84 & $5(2)$ & & \\
& Electronic & & $1(2)$ & & $\mathrm{ns}$
\end{tabular}

$\overline{\mathrm{n} \text { : size of sample, Md: Median, IQR: interquartile range, } \mathrm{z} \text { : z-score derived from Wilcoxon }}$ Signed-Rank Test $\alpha$ : level of significance, ns: not significant. 
Figure 1: Relationship between use of the journal collection and discipline

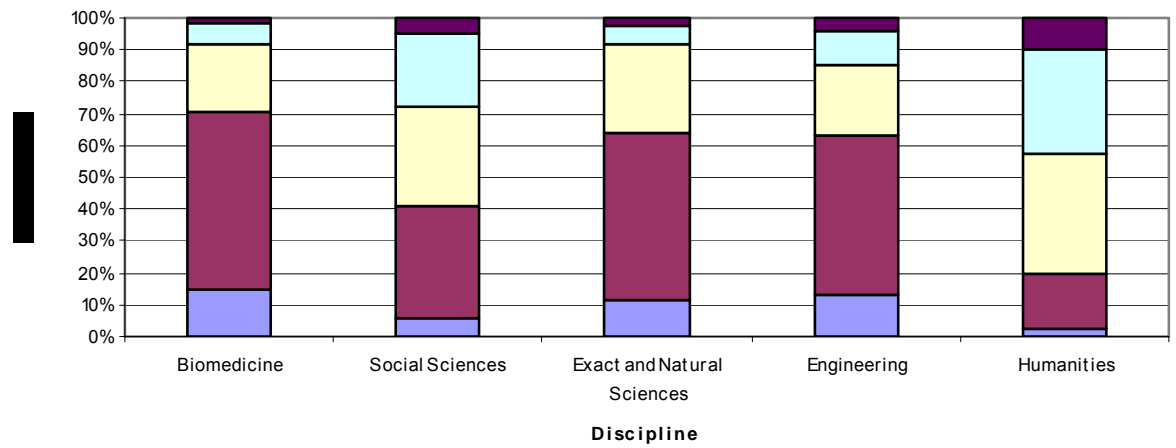

\begin{tabular}{|c|c|}
\hline Exclusively electronic & - Electronic and printed, but mainly electronic \\
\hline Bothelectronic and printed & 口 Electronic and printed, but mainly printed \\
\hline
\end{tabular}


Figure 2: Relationship between use of the journal collection and age

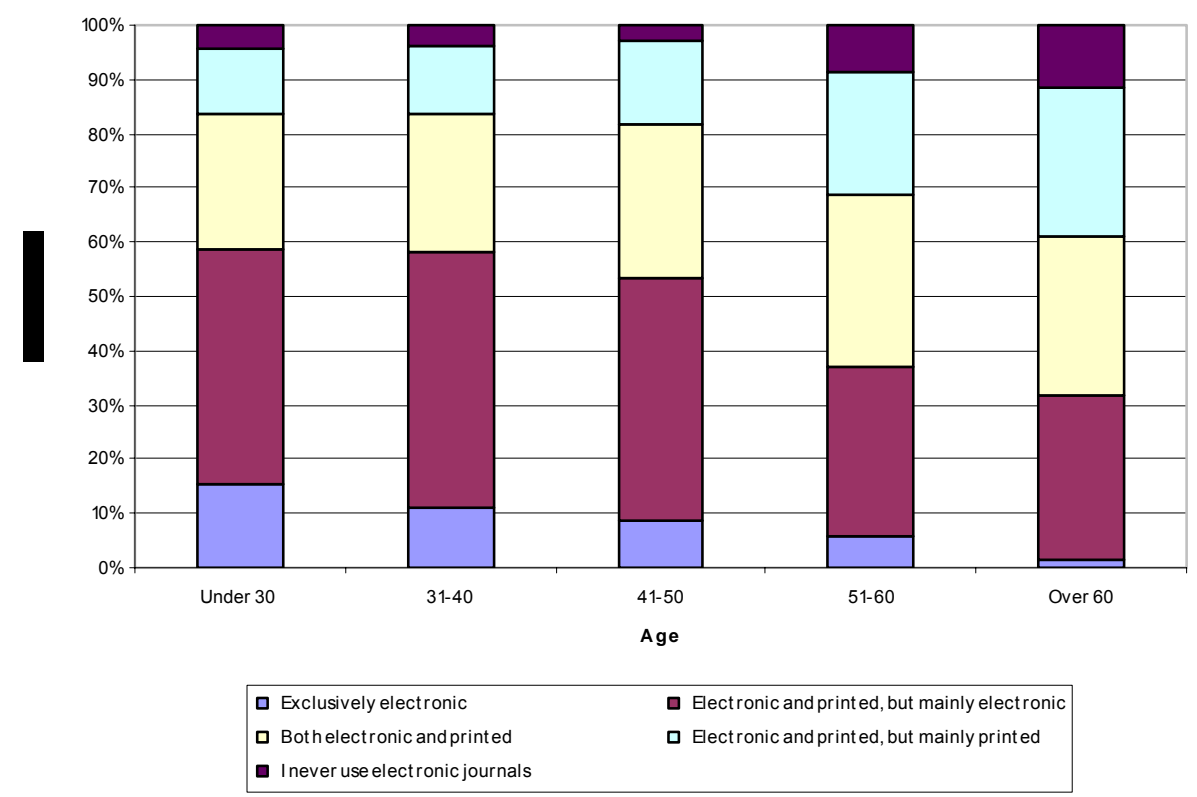


Figure 3: Reasons for using exclusively or mainly printed journals

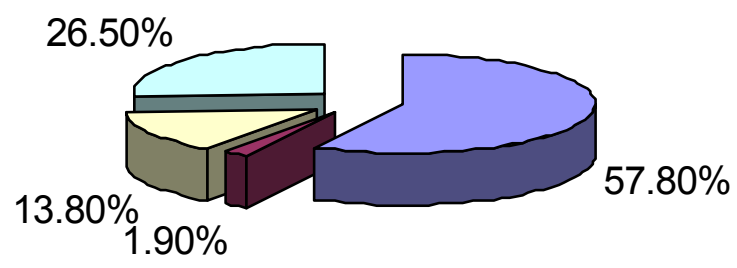

I am not familiar with electronic journals

$\square$ I do not have an Internet connection

$\square$ There are no electronic journals in my discipline $\square$ Other reasons 
Figure 4: Relationship between discipline and willingness to change to the electronic version

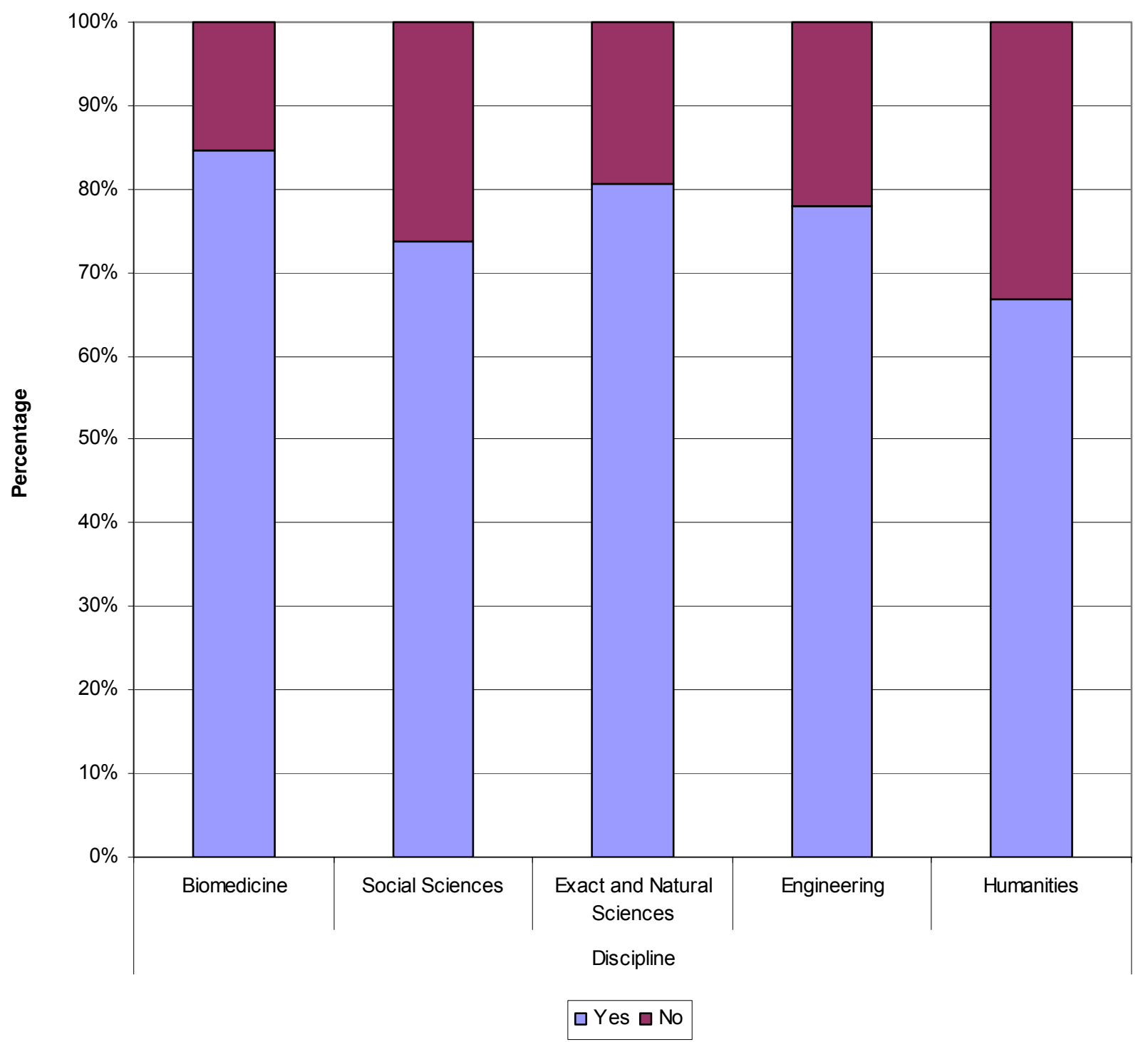


Figure 5: Relationship between age and willingness to change to the electronic version

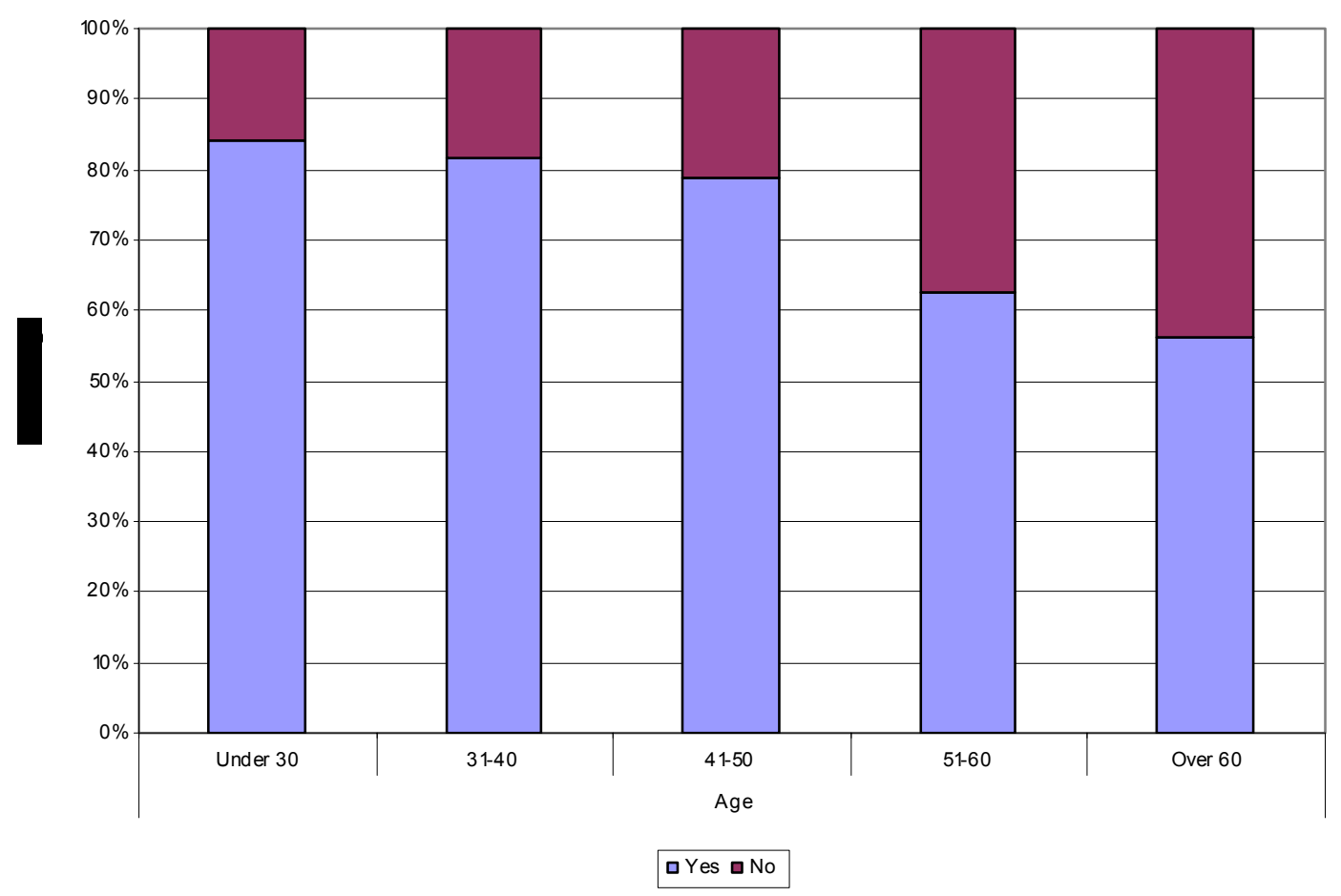


Figure 6: Relationship between discipline and reason for use

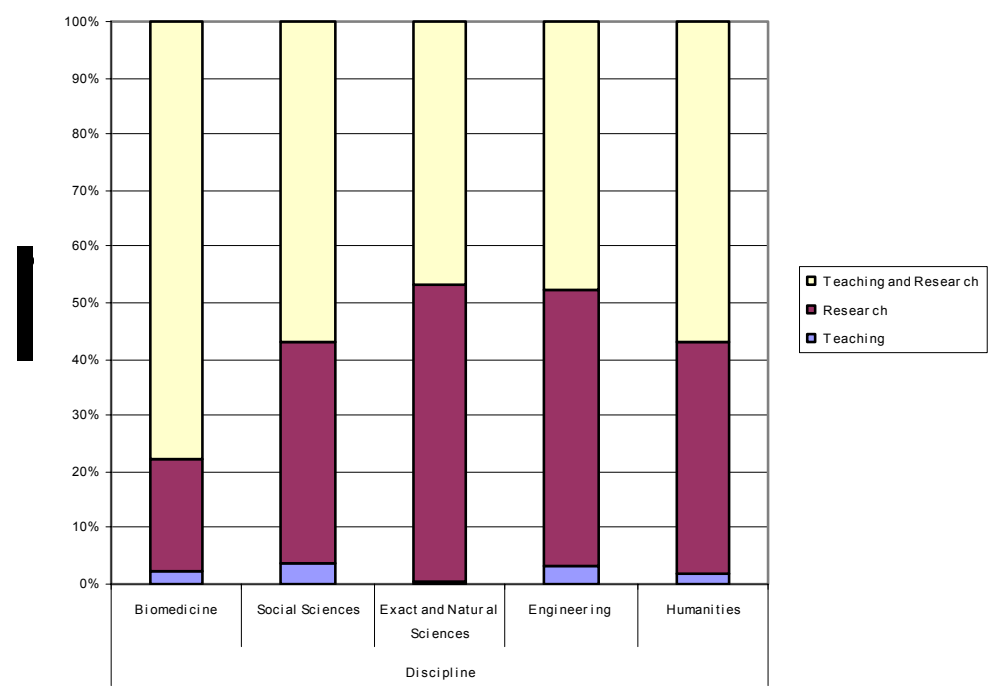


Figure 7: Relationship between age and reason for use

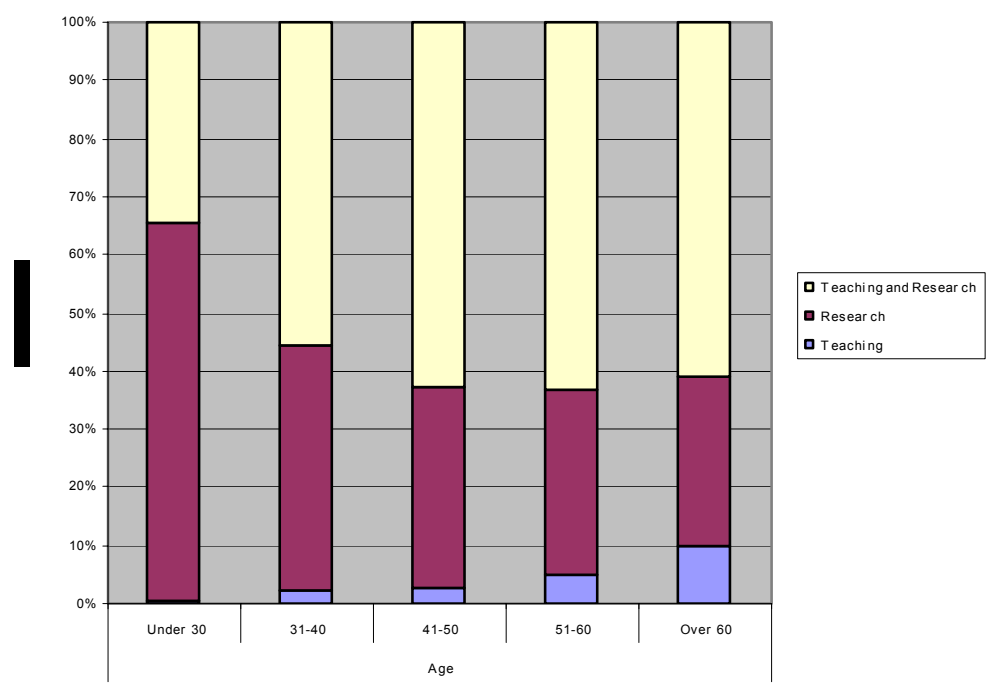


Figure 8: Relationship between discipline and expected future use of printed journals

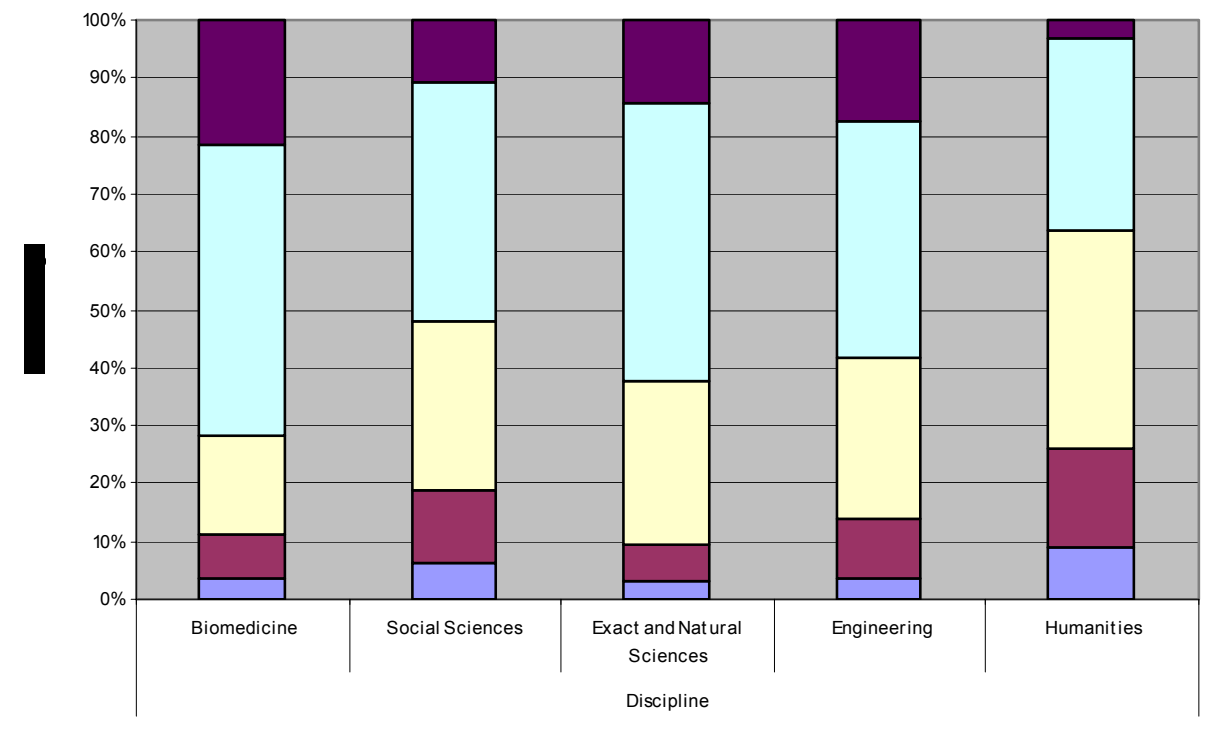

$\square$ Will increase considerably $\square$ Will increase to some extent $\mathbf{\square}$ Will not change $\mathbf{\square}$ I will use them less $\boldsymbol{\square}$ I will st op using them 
Figure 9: Relationship between age and expected future use of printed journals

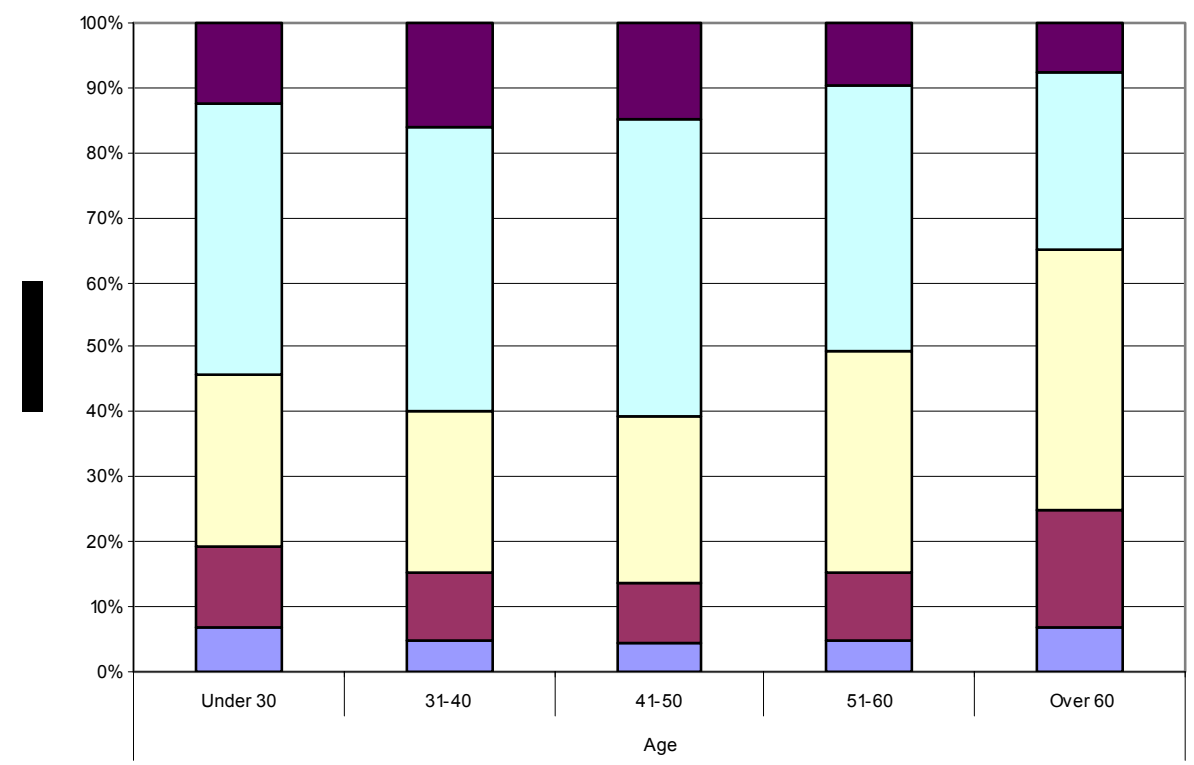

$\mathbf{\square}$ Will increase considerably $\mathbf{\square}$ Will increase to some ext ent $\mathbf{\square}$ Will not change $\mathbf{\square}$ I will use them less $\boldsymbol{\square}$ I will stop using them 